\title{
Age at spinal cord injury determines muscle strength
}

\section{Christine K. Thomas ${ }^{1,2,3 *}$ and Robert M. Grumbles ${ }^{1}$}

1 The Miami Project to Cure Paralysis, University of Miami Miller School of Medicine, Miami, FL, USA

${ }^{2}$ Department of Neurological Surgery, University of Miami Miller School of Medicine, Miami, FL, USA

${ }^{3}$ Department of Physiology and Biophysics, University of Miami Miller School of Medicine, Miami, FL, USA

\section{Edited by:}

Martin Oudega, University of

Pittsburgh, USA

\section{Reviewed by:}

Antonio Pereira, Federal University of

Rio Grande do Norte, Brazil

Martin Oudega, University of

Pittsburgh, USA

*Correspondence:

Christine K. Thomas, The Miami

Project to Cure Paralysis, University of

Miami Miller School of Medicine, 1095

NW 14 Tce, R48, Miami, FL 33136,

USA

e-mail:cthomas@miami.edu
As individuals with spinal cord injury (SCI) age they report noticeable deficits in muscle strength, endurance and functional capacity when performing everyday tasks. These changes begin at $\sim 45$ years. Here we present a cross-sectional analysis of paralyzed thenar muscle and motor unit contractile properties in two datasets obtained from different subjects who sustained a cervical $\mathrm{SCl}$ at different ages ( $\leq 46$ years) in relation to data from uninjured age-matched individuals. First, completely paralyzed thenar muscles were weaker when $\mathrm{C} 6 \mathrm{SCl}$ occurred at an older age. Muscles were also significantly weaker if the injury was closer to the thenar motor pools (C6 vs. C4). More muscles were strong ( $>50 \%$ uninjured) in those injured at a younger ( $\leq 25$ years) vs. young age (>25 years), irrespective of $\mathrm{SCl}$ level. There was a reduction in motor unit numbers in all muscles tested. In each $\mathrm{C} 6 \mathrm{SCl}$, only $\sim 30$ units survived vs. 144 units in uninjured subjects. Since intact axons only sprout $4-6$ fold, the limits for muscle reinnervation have largely been met in these young individuals. Thus, any further reduction in motor unit numbers with time after these injuries will likely result in chronic denervation, and may explain the late-onset muscle weakness routinely described by people with $\mathrm{SCl}$. In a second dataset, paralyzed thenar motor units were more fatigable than uninjured units. This gap widened with age and will reduce functional reserve. Force declines were not due to electromyographic decrements in either group so the site of failure was beyond excitation of the muscle membrane. Together, these results suggest that age at $\mathrm{SCl}$ is an important determinant of long-term muscle strength, and fatigability, both of which influence functional capacity.

Keywords: motoneuron death, muscle reinnervation, motor axon sprouting, muscle use, muscle fatigue, muscle strength

\section{INTRODUCTION}

In the United States, most traumatic spinal cord injuries occur in individuals who are 16-30 years old. However, more falls in older individuals have resulted in the average age at injury rising from 29 to 40 years over the last few decades (Jackson et al., 2004; NSCISC, 2013). Ostensibly, there are no differences in the numbers of intact axons or demyelination when traumatic human spinal cord injury (SCI) occurs at a young vs. old age ( $\geq 65$ years, Furlan et al., 2010). Gains in sensory and motor scores were also independent of age during the first year after human SCI, the time when most recovery occurs (Ditunno et al., 1992; Waters et al., 1993; Kirshblum et al., 2004; Fawcett et al., 2007; Furlan and Fehlings, 2009; Pouw et al., 2011). Yet functional recovery was poorer in older individuals ( $\geq 65$ years; Furlan and Fehlings, 2009).

Few animal studies have explored age-related differences after SCI. Like human studies, comparisons have largely been made between the young and the elderly. The results vary. Fiber tracts showed similar damage in young (2-3 months) and old rats (22-28 months) after partial dorsal hemisection (Jaerve et al., 2011). In contrast, pathology and demyelination were greater after spinal contusion, remyelination was reduced, and recovery of locomotor function was delayed in middle-aged (12 months) and old rats (24 months) compared to young rats (3 months; Siegenthaler et al., 2008). After thoracic cord hemisection, recovery of locomotor function was faster in young (40 days) and adult rats (60 days). Paw withdrawal was more frequent and faster in young (40 days) compared to adult (60 days) or middle-aged rats (12 months; Gwak et al., 2004). These latter results highlight functional differences occur early after SCI at young ages (40 and 60 days), drawing attention to descriptions of other age-related dysfunction after human SCI.

As people with SCI age, they report new muscle weakness, fatigue, and pain at $\sim 45$ years. These declines in physical function significantly impact independence, and quality of life. More assistance is needed with daily tasks (Gerhart et al., 1993; Kemp and Thompson, 2002; McColl et al., 2002; Amsters et al., 2005; Krause and Coker, 2006; Charlifue et al., 2010). The biological mechanisms underlying this late-onset impairment are unknown. Thus, we have no rationale strategy to address these aged-related declines in muscle function after human SCI. Is this muscle dysfunction at $\sim 45$ years impacted by the age at which SCI occurs? 
Or do ongoing changes in the years after injury (SCI duration) also contribute to this new muscle dysfunction?

Contusive SCI in humans damages axons and myelin. Grey matter is also destroyed at the injury epicenter (Bunge et al., 1993; Hayes and Kakulas, 1997; Guest et al., 2005), resulting in partial or complete muscle denervation (Peckham et al., 1976b; Thomas, 1997; Thomas et al., 1997; Mulcahey et al., 1999; Bryden et al., 2004; Kern et al., 2005). Survival of both motoneurons and interneurons is important to retain muscle innervation and use, both of which influence muscle strength, fatigue, and ultimately function (Needham-Shropshire et al., 1997; Thomas and Zijdewind, 2006). In this study, our aim was to make a crosssectional analysis of paralyzed thenar muscle and motor unit contractile properties in two datasets obtained from different subjects who sustained a cervical SCI at different ages. Examining the extent of muscle weakness when SCI occurs at a younger vs. young age provides some indication of the importance of motoneuron death on muscle force (Thomas and Zijdewind, 2006) since near elimination of activity reduces forces to $40-50 \%$ initial (Tower, 1937; Pierotti et al., 1991). We have also compared thenar strength and fatigue in relation to age at the single motor unit level. This approach shows how well intact motoneurons function independently of confounds that impact muscle strength (e.g., motoneuron death).

\section{METHODS}

The whole muscle and motor unit data presented here have been compiled from our published studies. Only a synopsis of the methods is given. All of the experiments were approved by the University of Miami Investigational Review Board. All subjects gave written informed consent before participation in the experiments.

\section{SETUP AND PROTOCOL FOR THENAR MUSCLE FORCE AND EMG MEASUREMENTS}

All subjects sat in a chair or wheelchair with the test arm resting to the side and supported in a vacuum cast (Thomas, 1997). The hand rested in modeling clay, palm up, and was held in place by a metal plate and Velcro. A transducer was aligned with the thumb and used to measure abduction and flexion forces at right angles. Resultant force was calculated. EMG data were also recorded from the distal and proximal muscle surfaces using wire electrodes taped across the entire muscle (Westling et al., 1990). The median nerve was stimulated just proximal to the wrist using pulses of increasing intensity (1-10 $\mathrm{mA}$ steps) until maximal compound muscle action potentials (M-waves) were evoked (no further increase in EMG with an increase in stimulus intensity). The maximal force was then evoked by $1 \mathrm{~s}$ of stimulation at $50 \mathrm{~Hz}$ using a supramaximal stimulation intensity (20-50\% greater than the level that produced a maximal Mwave). Force and EMG were sampled online at $400 \mathrm{~Hz}$ and $3200 \mathrm{~Hz}$, respectively, using a SC/Zoom system (Umeå University, Sweden).

Maximal thenar muscle forces (baseline to peak) were measured using Zoom software. Data were obtained from 42 paralyzed muscles. These people had SCI at C4 $(n=6)$, C5 $(n=13)$ or C6 $(n=23)$ due to a diving accident $(n=18)$, a motor vehicle accident $(n=14)$, gunshot $(n=4)$, a sports accident $(n=5)$ or a fall ( $n=1$; Thomas, 1997; Zijdewind and Thomas, 2001; Griffin et al., 2002; Thomas et al., 2003; Butler et al., 2004). Results were separated into two groups according to whether the person had been $\leq 25$ years (termed, Younger) or $>25$ years (termed, Young) at the time of SCI, respectively. This separation was used because maximal evoked thenar force was 38\% uninjured at 25 years (Figure 1), close to the reduction expected for an inactive muscle (Tower, 1937; Pierotti et al., 1991). Table 1 lists the mean ( \pm SE) age at SCI and SCI duration by injury level and age group. Maximal forces from paralyzed muscles were normalized to data obtained from 40 muscles of uninjured subjects matched by age and sex.

\section{THENAR MOTOR UNIT COUNTS}

The experimental arrangement and data collection were the same as described for muscle force and EMG measurements but the protocol differed. Five pulses at $1 \mathrm{~Hz}$ were delivered to the median nerve at increasing intensities $(0.1 \mathrm{~mA}$ steps $)$ from subthreshold (no response) to supramaximal intensity. Responses with similar EMG and force were averaged. The averaged data was ranked from weak to strong force and overlayed. The number of force steps was used as an estimate of the motor unit count. Data were obtained from six men who sustained a SCI at C5 $(n=1)$, C6 $(n=3)$ or C7 $(n=2)$ from a diving accident $(n=3)$, a motor vehicle accident $(n=2)$ or a fall $(n=1)$. Age at SCI and SCI duration ranged from 21-46 years and 3-15 years, respectively (Thomas et al., 2002).

\section{THENAR MOTOR UNIT FORCES}

Unit forces were recorded in response to intraneural stimulation of thenar motor axons in the median nerve (Westling et al., 1990). Each person reclined on a bed with the test arm and hand resting to the side. Both the unitary EMG and force were recorded as described for whole muscle measurements. Maximal motor unit force was evoked by stimulation at 30,40 , or $50 \mathrm{~Hz}$ for $1 \mathrm{~s}$ or at $100 \mathrm{~Hz}$ for $0.5 \mathrm{~s}$. Fatigue was induced by delivering 13 pulses at $40 \mathrm{~Hz}$ each second for $2 \mathrm{~min}$. The force fatigue indices were calculated every $20 \mathrm{~s}$ as the ratio between the current force and the initial force. EMG area fatigue indices were calculated similarly using the first potential of the respective stimulus trains. Data were obtained from 12 individuals with SCI (Häger-Ross et al., 2006; Klein et al., 2006; Thomas et al., 2010) at C4 $(n=4)$, C5 $(n=3)$ or C6 $(n=6)$ from gunshot $(n=1)$, a diving accident $(n=3)$, a motor vehicle accident $(n=5)$, horseback riding $(n=2)$ or a fall $(n=1)$. Data were divided by age, as described for whole muscle forces. Age at SCI averaged $( \pm S E)$ $19 \pm 1$ years for the younger group, and $34 \pm 3$ years for the young group, respectively. The corresponding values for SCI duration were $10 \pm 2$ years, and $9 \pm 2$ years, respectively. These data were compared to that obtained from 12 uninjured subjects $(23 \pm$ 1 years and $39 \pm 7$ years for the younger and young groups, respectively).

\section{STATISTICS}

Mean $( \pm$ SE) data are given. The relationships between maximal evoked force and age at C6 SCI, and between muscle force and motor unit counts were analyzed using least squares linear 

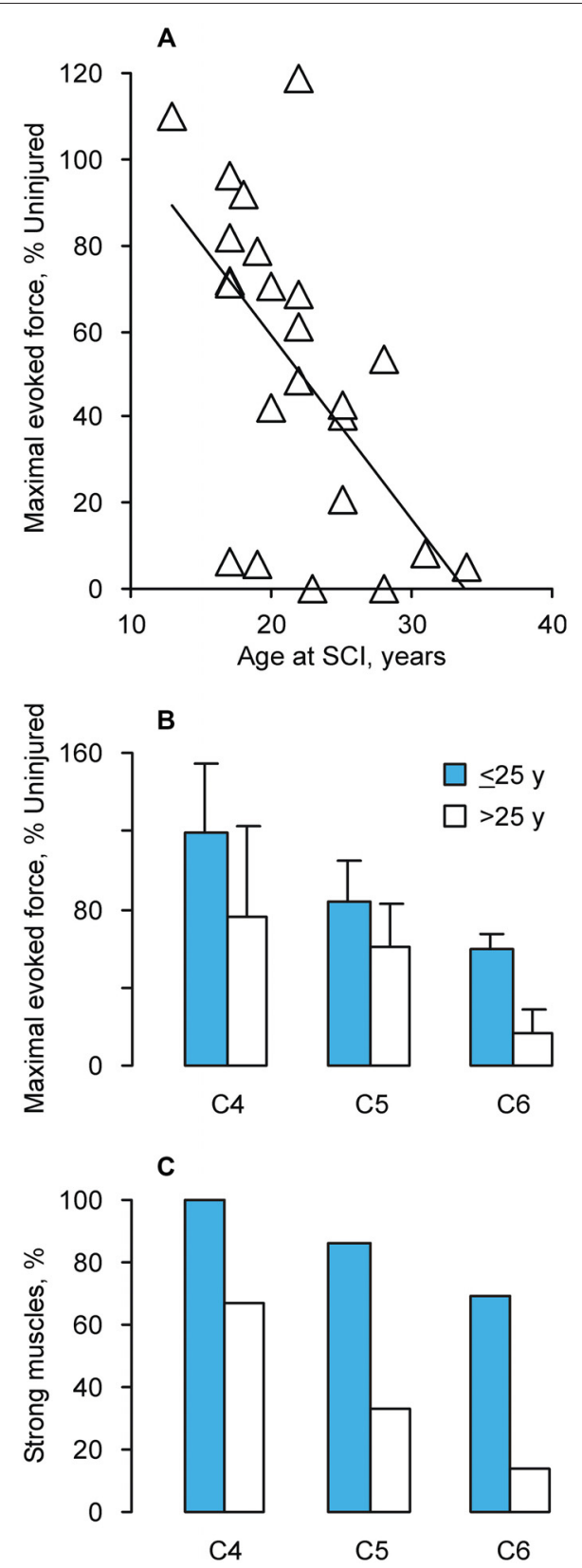

FIGURE 1 | (A) Maximal evoked force vs. age at which 6 6 SCl occurred $\left(n=23\right.$ muscles; $\left.y=-4.28 x+145.07, R^{2}=0.36\right)$. Mean $(+\mathrm{SE})$ forces for uninjured 20 and 30 year old men were $26.7 \pm 1.6 \mathrm{~N}$ and $22.9 \pm 4.2 \mathrm{~N}$, respectively. The corresponding data for women were $16.4 \pm 1.7 \mathrm{~N}$ and $18,7 \pm 1.8 \mathrm{~N}$. (B) Mean ( \pm SE) maximal evoked thenar force $(n=42$ muscles) normalized to age and sex-matched uninjured data ( $n=40$ muscles). (C) Percentage of strong muscles (>50\% uninjured force), separated by SCl level and age at SCl (Younger: $\leq 25$ years; Young: $>25$ years; $n=42$ muscles)

regression. The proportion of weak vs. strong muscles was compared using Chi square analysis. Two-way ANOVA was used to compared mean muscle force in relation to age at SCI and level of SCI, as well motor unit force in relation to group (SCI vs. Uninjured) and age. Motor unit force and EMG area fatigue
Table 1 | Mean $( \pm \mathrm{SE})$ age by $\mathrm{SCl}$ level and group.

\begin{tabular}{lcccccc}
\hline Group & \multicolumn{3}{c}{ Younger } & \multicolumn{3}{c}{ Young } \\
\hline $\begin{array}{l}\mathrm{SCl} \text { level } \\
\begin{array}{l}\text { Age at SCl, } \\
\text { years }\end{array}\end{array}$ & $22 \pm 2$ & $21 \pm 1$ & $20 \pm 1$ & $39 \pm 1$ & $31 \pm 2$ & $30 \pm 1$ \\
$\begin{array}{l}\mathrm{SCl} \text { duration, } \\
\text { years }\end{array}$ & $8 \pm 2$ & $9 \pm 2$ & $11 \pm 2$ & $6 \pm 2$ & $4 \pm 2$ & $6 \pm 2$ \\
\hline
\end{tabular}

indices were examined over time using two way repeated measures ANOVA.

\section{RESULTS}

PARALYZED THENAR MUSCLES WERE STRONGER WHEN YOUNGER INDIVIDUALS SUSTAINED HIGH LEVEL SPINAL CORD INJURY (SCI)

The maximal evoked thenar force declined when C6 SCI occurred in older individuals ( $p=0.003$, Figure 1A). The regression analysis showed that the expected force would be $59 \%, 38 \%$, and $17 \%$ of uninjured values when SCI occurred at 20, 25, and 30 years of age, respectively. For comparison, the mean maximal thenar muscle force for 30 year old uninjured men $(22.9 \pm 4.2 \mathrm{~N})$ was $85 \%$ of the mean measured for 20 year old men $(26.7 \pm 1.6 \mathrm{~N})$. There was no significant relationship between evoked force and SCI duration ( $p=0.42)$ or current biological age $(p=0.45)$.

The maximal evoked force from completely paralyzed thenar muscles was also significantly lower when the SCI was closer to the thenar motor pools ( $p=0.035$, C6 vs. C4) and almost significant when the person was younger when injured $(\leq 25$ years, $p=0.052$, Figure 1B). To estimate the prevalence of muscle strength vs. weakness, these same data were separated by force. More muscles were strong ( $>50 \%$ uninjured force) if the person was younger when injured, irrespective of injury level $(p<0.001$, Figure 1C).

\section{MOTONEURON SURVIVAL MAINTAINED MUSCLE STRENGTH}

The number of thenar motor units was correlated positively with maximal force ( $p=0.118, n=6$ muscles, Figure 2$)$. Although not significant, $70 \%$ of the force variability was accounted for by motor unit number. Motoneuron survival is therefore an important determinant of muscle force. Reductions in thenar motor unit numbers occurred in each SCI case (range: 15-83 units) since estimates for uninjured individuals averaged $144 \pm 16$ (Yang et al., 1990; Thomas et al., 2002). Only 30 units survived each C6 SCI ( $\sim 20 \%$ uninjured) with maximal muscle force ranging from $62 \%$ to $105 \%$ of uninjured values. Since intact axons only sprout 4-6 fold (Brown et al., 1981), the limits for muscle reinnervation have largely been met in these individuals who ranged in age from 25-53 years, when studied. Any further reduction in motor unit numbers with time after these injuries will likely result in chronic denervation, which is one factor that may explain the late-onset muscle weakness routinely described by people with SCI.

\section{THENAR MOTOR UNITS WERE LESS FATIGABLE WHEN SPINAL CORD INJURY (SCI) WAS SUSTAINED AT A YOUNGER AGE}

The initial mean maximal force of paralyzed thenar motor units was weaker than that for units of uninjured subjects $(p=0.019$; Häger-Ross et al., 2006). Motor unit forces were also weaker with 


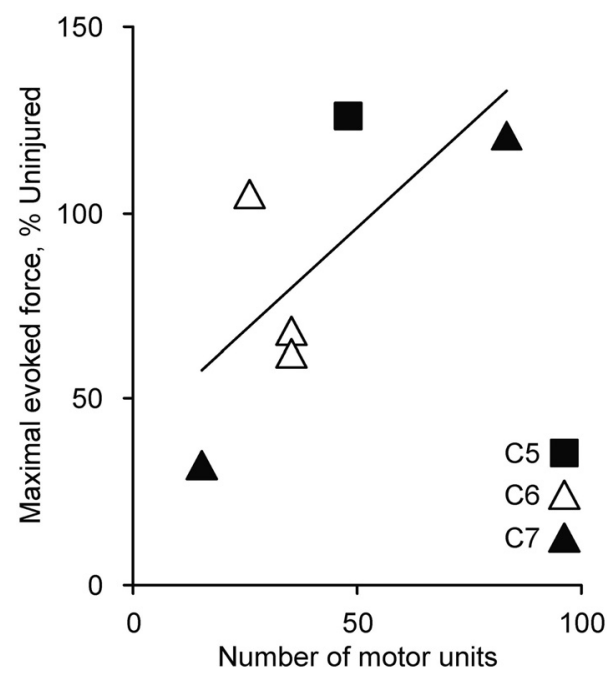

FIGURE 2 | Number of motor units in relation to maximal thenar muscle force evoked by supramaximal median nerve stimulation and expressed relative to uninjured means ( $n=6$ subjects).

age $(p=0.023)$, but there was no interaction between group and age (Figure 3A). Paralyzed motor units from individuals injured at a younger age generated $68 \%$ of the force produced by units from age-matched uninjured people. The corresponding value for young SCI subjects was $62 \%$.

In contrast, paralyzed motor units were more fatigable than uninjured units and the gap widened with age. Mean force declines (fatigue) differed by group $(p<0.001)$ and time $(p<0.001$, Figure 3B). The time effects also differed among groups $(p<0.001)$. After 2 min of stimulation, paralyzed motor units from individuals injured at a younger age had fatigue indices that were $44 \%$ lower than units from age-matched uninjured people, whereas the fatigue indices were $70 \%$ lower for individuals injured when they were young. Force declines reached significance at $20 \mathrm{~s}$ for the young SCI group, at $40 \mathrm{~s}$ for the younger SCI group, at $60 \mathrm{~s}$ for the younger uninjured group, and at $80 \mathrm{~s}$ for the young uninjured group. Force declines were greater for the young SCI group compared to both uninjured groups (from 40-120 s) and the younger SCI group (from 60-120 s). The younger SCI group fatigued more than both uninjured groups from $80-120 \mathrm{~s}$. The younger uninjured group fatigued more than the young uninjured group at 120 s. However, the EMG area increased significantly $(p<0.001)$ from $20-120$ s, suggesting that the force declines were distal to excitation of the sarcolemma (Figure 3C; Klein et al., 2006). The mean EMG area fatigue indices recorded from the young SCI group were higher than those from both uninjured groups $(p=0.006)$ but there was no interaction between group and time, possibly because larger increases in both EMG potential duration and area occur in more fatigable units (Klein et al., 2006; Thomas et al., 2006).

\section{DISCUSSION}

Our data show that age at SCI impacts both muscle strength and motor unit fatigue, even in young adults. After SCI at C6, maximal thenar force was reduced to $59 \%$ of uninjured if the person was

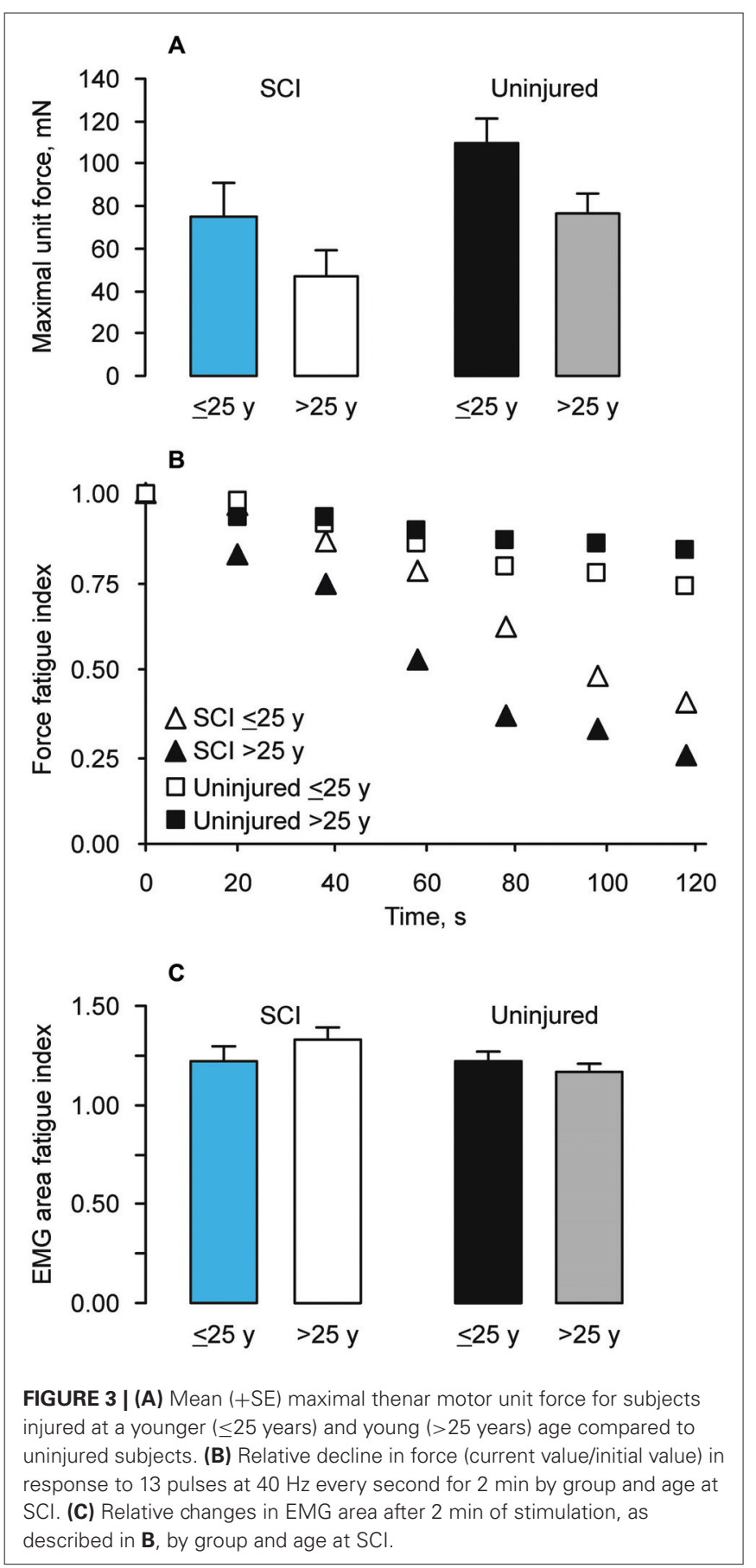

20 years old. Force was $42 \%$ lower (17\% uninjured) when the SCI occurred at 30 years of age. No relationship was evident between force and the duration of SCI. These data indicate that age at the time of SCI has a strong influence on recovery of muscle strength. At the single motor unit level, age weakened unit forces in both SCI and uninjured subjects. However, paralyzed units were more fatigable, especially in people injured at $>25$ years of age. Greater muscle fatigue may be shaped by time-dependent changes. 


\section{MUSCLE STRENGTH DEPENDS ON INNERVATION}

The compressive and/or contusive forces that commonly occur with human SCI destroy grey matter at the lesion epicenter, kill motoneurons, and denervate muscles (Bunge et al., 1993; Hayes and Kakulas, 1997; Thomas and Zijdewind, 2006). Compensatory mechanisms exist when the denervation is incomplete. Intact axons are challenged to sprout within muscle to innervate up to 4-6 times more muscle fibers (Brown et al., 1981; Yang et al., 1990; Thomas et al., 1997). Thus, if only a few motoneurons die, intramuscular sprouting and reinnervation will resolve any muscle strength deficits. However, force deficits do become evident when $70-80 \%$ of motoneurons die. The limits of axon sprouting are met, leaving some muscle fibers denervated chronically.

Our data show that most individuals who sustained SCI when they were older than 25 years had forces below 50\% uninjured, particularly when the SCI was close to the test motor pools (Figure 1). Motoneuron survival was also an important determinant of muscle strength (Figure 2). These novel data raise many questions about the recovery of muscle function after SCI. Do more motoneurons die when SCI occurs in a person older than 25 years, inducing greater muscle weakness? Does age influence the robustness of intramuscular sprouting? Does the sprouting response in muscle differ if a young vs. older motoneuron has lost or retained most of its synaptic inputs after SCI? To our knowledge, none of these questions have been explored in relation to age at SCI. The more extensive paralysis that occurred in adults vs. children with poliomyelitis suggests an age-related susceptibility of motoneurons to death in this situation (Weinstein, 1957; Jubelt et al., 1980). Sprouting of central axons is compromised in old (22-28 months) vs. young rats (2-3 months) after partial dorsal hemisection (Jaerve et al., 2011). Recovery of muscle function is better after peripheral nerve section in children compared to young adults (Rosen and Lundborg, 2001; Chemnitz et al., 2013; Galanakos et al., 2013). More frequent and faster paw withdrawal after spinal hemisection in young (40 days) compared to adult (60 days) and middle-aged rats (12 months; Gwak et al., 2004) suggest that early responses to SCI change recovery of muscle function in younger animals. Clearly, new studies are needed to define the relevance of these results to recovery of muscle function when SCI occurs in different aged humans.

\section{MUSCLE STRENGTH AND FATIGUE DEPEND ON USE}

Ongoing neural activity due to spasticity, continuous ongoing activity in the relaxed state, changes in muscle length, and loading may be sufficient to counter atrophy in some paralyzed muscles (e.g., Figure 1B, Younger C4 SCI; Thomas, 1997). However, reduced amounts of daily activity will contribute to muscle weakness. Our data show that motor units were weaker with paralysis and with age, but the force declines were independent of group (SCI vs. Uninjured; Figure 3A). Motor units in uninjured hand muscles are activated at low intensities each day (Kern et al., 2001; Thomas et al., 2005). Ongoing spontaneous motor unit activity is also common in paralyzed thenar muscles and unit firing rates are low (Stein et al., 1990; Zijdewind and Thomas, 2001, 2012). Thus, activity may be less important than spinal pathology in determining age-related differences in muscle strength after SCI. Strength declines from chronic use of baclofen (Thomas et al.,
2010) are less likely to explain force differences because $58 \%$ and $54 \%$ of the units in the younger and young SCI datasets were influenced by this medication, respectively. Both SCI groups also included data from individuals with C4, C5 or C6 SCI, minimizing effects from injury level.

Fatigability of paralyzed units increased with age, whereas motor units were less fatigable in young uninjured adults (Figure 3B). The different force declines did not reflect failure of neuromuscular transmission because potentiation of EMG area with repeated stimulation was a consistent finding across groups irrespective of age (Figure 3C; Klein et al., 2006). With time, the proportion of fast type fibers increases in paralyzed muscles, as does their fatigability, largely due to reductions in muscle activity (Peckham et al., 1976a; Stein et al., 1992; Burnham et al., 1997; Shields and Dudley-Javoroski, 2006; Thomas and Zijdewind, 2006). If greater destruction of spinal circuitry occurs with SCI and age, it may be harder to activate affected muscles, increasing their fatigability. In healthy muscles, the least active motor units are the most fatigable ones (Hennig and Lømo, 1985; Thomas et al., 1991; Klein et al., 2010).

\section{SPINAL CORD INJURY (SCI) LEAVES MANY MUSCLES CLOSE TO THE THRESHOLD FOR DYSFUNCTION}

Another striking feature of our data is the wide variation in strength of completely paralyzed muscles (Figure 1). Each of these muscles would receive a manual muscle score of zero so clinical evaluations miss these age-related force differences completely. Knowledge of paralyzed muscle force generating capacity is important when patterned electrical stimulation is to be used to restore function to these muscles, an approach which people with SCI value (Brown-Triolo et al., 2002; Anderson, 2009), but this strategy would only be valuable for paralyzed muscles that can generate strong enough forces for useful function. In contrast to the data presented here, the reports of new muscle dysfunction at $\sim 45$ years probably arise from muscles that are weakened, but left under voluntary control by SCI. In muscles under voluntary control, manual muscle scores can range from 1 to 5 but any given manual muscle score is associated with a wide range of voluntary forces. In triceps brachii for example, the average force associated with a manual muscle score of 3 , which is considered useful for function because the test joint can be moved through its full range of motion against gravity, ranged from $2-19 \%$ of the maximal voluntary force of uninjured subjects. Force ranged from 0-16\% of maximal force for a score of 2 (full elbow extension without gravity), so for some muscles, shortening was felt and they generated EMG but this activity resulted in no measurable force (Needham-Shropshire et al., 1997). These data show that the voluntary forces measured in triceps brachii after SCI overlapped for different scores, making it important to question whether the low resolution of manual muscle scores (5 possible levels) has limited the ability to discern age-related differences in voluntary muscle strength. This is even more of an issue when published data are pooled across many muscles rather than presented for each muscle.

Our data show that SCI at a young age ( $\leq 40$ years) leaves many muscles near the threshold for clinical symptoms (Figure 1; 10 $20 \%$ uninjured force; McComas et al., 1993). Both the weakness 
and fatigability of paralyzed muscles will limit performance in applications involving patterned electrical stimulation because more muscle has to be used to generate a given force. Only small decrements in maximal force after injury or from fatigue would result in meaningful declines in muscle function. Thus, age at SCI is a risk factor that likely affects early onset ( $\sim 45$ years) muscle weakness and fatigue after SCI. But the underlying mechanisms are unknown. Obviously, trauma of the spinal cord will perturb multiple factors and pathways essential for neuron survival and plasticity of local spinal and neuromuscular circuits. Intrinsic neuron survival and axon growth are developmentally regulated, and generally become less robust in early adulthood. After injury, less axon regeneration occurs from mature neurons than young ones (Filbin, 2006). Thus, SCI at an older age may immediately result in less optimal neuroprotection and retention of spinal circuits.

It is also conceivable that slow changes over many years induce late-onset muscle dysfunction after SCI. This may involve alterations in the original pathology. For example, syrinx development can take several years (Brodbelt and Stoodley, 2003). After age 40 , activity-based force declines average $1.5 \%$ per year in the uninjured (Clement, 1974; Frontera et al., 1991; Lauretani et al., 2003; Frederiksen et al., 2006) so weakness may reflect less muscle use. Alternatively, regressive changes in motor unit function may be attributable to chronic overuse of weak muscles that have been partially denervated by SCI. In poliomyelitis, residual motor units are used excessively (Borg et al., 1988), but as these individuals age motor unit numbers unexpectedly decrease at up to twice the rate that occurs in healthy subjects (McComas et al., 1997; Grimby et al., 1998; Gonzalez et al., 2010). Ongoing cycles of denervation and reinnervation occur in muscles of people with post polio syndrome (Hayward and Seaton, 1979; Borg et al., 1988; Grimby et al., 1998) so chronic intramuscular axon growth in over exerted motor units could also undermine motor unit integrity. Traumatic SCI involves additional central damage compared to that which occurs with poliomyelitis. Thus, greater central dysfunction and peripheral demands after SCI and age may elevate calcium levels in motoneurons to excess, resulting in mitochondrial dysfunction, damage and death (van den Bosch et al., 2006; Gleichmann and Mattson, 2011; Jacobs et al., 2013). Motoneuron survival with age may therefore rely on managing metabolic load in relation to the growth demands of reinnervated motor units. Consistent with this idea, partial muscle denervation in rats 3 weeks after botulinum toxin-induced muscle paralysis resulted in more motoneuron death than botulinum toxin or partial denervation alone (White et al., 2000). Following nerve crush, unexpected motoneuron death also occurred in mice overexpressing GAP43, which causes constant sprouting (Harding et al., 1999).

\section{THE IMPACT OF AGE AT SPINAL CORD INJURY (SCI) ON MUSCLE FUNCTION IS UNDERSTUDIED}

We lack substantive evidence on how spinal pathology, muscle innervation (motor unit number, force), and muscle use change with SCI and age. Our data emphasizes that this information is needed throughout the lifespan, not just in the young and the elderly. All of these processes are important determinants of strength and how well a muscle can be used for daily tasks. These unresolved issues are key questions to answer for the aging SCI population because muscle contractions define functional independence and other body functions (e.g., blood glucose levels, bone strength; Vandervoort, 2002; Pedersen, 2009). This kind of information is needed to facilitate design of interventions to remedy age-related declines in muscle function after SCI. If muscle weakness is primarily determined by early motoneuron survival, sustained neuroprotection has to become a priority. If overuse of surviving motoneurons predisposes them to death, as suggested with post polio syndrome, exercise has to be tailored for long-term muscle health.

\section{AUTHOR CONTRIBUTIONS}

Christine K. Thomas: Project conception and design, data acquisition, analysis, and summary, review of literature, manuscript writing. Robert M. Grumbles: Project conception and design, review of literature, manuscript writing.

\section{ACKNOWLEDGMENTS}

This research was funded by the Craig Nielsen Foundation (\#258576), The National Institutes of Health (NS-30226) and The Miami Project to Cure Paralysis.

\section{REFERENCES}

Amsters, D. I., Pershouse, K. J., Price, G. L., and Kendall, M. B. (2005). Long duration spinal cord injury: perceptions of functional change over time. Disabil. Rehabil. 27, 489-497. doi: 10.1080/09638280400018478

Anderson, K. D. (2009). Consideration of user priorities when developing neural prosthetics. J. Neural Eng. 6:55003. doi: 10.1088/1741-2560/6/5/055003

Borg, K., Borg, J., Edstrom, L., and Grimby, L. (1988). Effects of excessive use of remaining muscle fibers in prior polio and LV lesion. Muscle Nerve 11, 12191230. doi: $10.1002 /$ mus.880111206

Brodbelt, A. R., and Stoodley, M. A. (2003). Post-traumatic syringomyelia: a review. J. Clin. Neurosci. 10, 401-408. doi: 10.1016/S0967-5868(02)00326-0

Brown, M. C., Holland, R. L., and Hopkins, W. G. (1981). Motor nerve sprouting. Annu. Rev. Neurosci. 4, 17-42. doi: 10.1146/annurev.ne.04.030181.000313

Brown-Triolo, D. L., Roach, M. J., Nelson, K., and Triolo, R. J. (2002). Consumer perspectives on mobility: implications for neuroprosthesis design. J. Rehabil. Res. Dev. 39, 659-669.

Bryden, A. M., Kilgore, K. L., Lind, B. B., and Yu, D. T. (2004). Triceps denervation as a predictor of elbow flexion contractures in C5 and C6 tetraplegia. Arch. Phys. Med. Rehabil. 85, 1880-1885. doi: 10.1016/j.apmr.2004.01.042

Bunge, R. P., Puckett, W. R., Becerra, J. L., Marcillo, A., and Quencer, R. M. (1993). Observations on the pathology of human spinal cord injury. A review and classification of 22 new cases with details from a case of chronic cord compression with extensive focal demyelination. Adv. Neurol. 59, 75-89.

Burnham, R., Martin, T., Stein, R., Bell, G., Maclean, I., and Steadward, R. (1997). Skeletal muscle fibre type transformation following spinal cord injury. Spinal Cord 35, 86-91. doi: 10.1038/sj.sc.3100364

Butler, J. E., Ribot-Ciscar, E., Zijdewind, I., and Thomas, C. K. (2004). Increased blood pressure can reduce fatigue of thenar muscles paralyzed after spinal cord injury. Muscle Nerve 29, 575-584. doi: 10.1002/mus.20002

Charlifue, S., Jha, A., and Lammertse, D. (2010). Aging with spinal cord injury. Phys. Med. Rehabil. Clin. N. Am. 21, 383-402. doi: 10.1016/j.pmr.2009.12.002

Chemnitz, A., Bjorkman, A., Dahlin, L. B., and Rosen, B. (2013). Functional outcome thirty years after median and ulnar nerve repair in childhood and adolescence. J. Bone Joint Surg. Am. 95, 329-337. doi: 10.2106/jbjs.1.00074

Clement, F. J. (1974). Longitudinal and cross-sectional assessments of age changes in physical strength as related to sex, social class and mental ability. J. Gerontol. 29, 423-429. doi: 10.1093/geronj/29.4.423

Ditunno, J. F. Jr., Stover, S. L., Freed, M. M., and Ahn, J. H. (1992). Motor recovery of the upper extremities in traumatic quadriplegia: a multicenter study. Arch. Phys. Med. Rehabil. 73, 431-436. 
Fawcett, J. W., Curt, A., Steeves, J. D., Coleman, W. P., Tuszynski, M. H., Lammertse, D., et al. (2007). Guidelines for the conduct of clinical trials for spinal cord injury as developed by the ICCP panel: spontaneous recovery after spinal cord injury and statistical power needed for therapeutic clinical trials. Spinal Cord 45, 190205. doi: $10.1038 /$ sj.sc.3102007

Filbin, M. T. (2006). Recapitulate development to promote axonal regeneration: good or bad approach? Philos. Trans. R. Soc. Lond. B Biol. Sci. 361, 1565-1574. doi: 10.1098/rstb.2006.1885

Frederiksen, H., Hjelmborg, J., Mortensen, J., McGue, M., Vaupel, J. W., and Christensen, K. (2006). Age trajectories of grip strength: cross-sectional and longitudinal data among 8,342 Danes aged 46 to 102. Ann. Epidemiol. 16, 554562. doi: 10.1016/j.annepidem.2005.10.006

Frontera, W. R., Hughes, V. A., Lutz, K. J., and Evans, W. J. (1991). A cross-sectional study of muscle strength and mass in 45- to 78-yr-old men and women. J. Appl. Physiol. 71, 644-650.

Furlan, J. C., and Fehlings, M. G. (2009). The impact of age on mortality, impairment and disability among adults with acute traumatic spinal cord injury. $J$. Neurotrauma 26, 1707-1717. doi: 10.1089/neu.2009-0888

Furlan, J. C., Bracken, M. B., and Fehlings, M. G. (2010). Is age a key determinant of mortality and neurological outcome after acute traumatic spinal cord injury? Neurobiol. Aging 31, 434-446. doi: 10.1016/j.neurobiolaging.2008.05.003

Galanakos, S. P., Zoubos, A. B., Mourouzis, I., Ignatiadis, I., Bot, A. G., and Soucacos, P. N. (2013). Prognostic scoring system for peripheral nerve repair in the upper extremity. Microsurgery 33, 105-111. doi: 10.1002/micr.22000

Gerhart, K. A., Bergstrom, E., Charlifue, S. W., Menter, R. R., and Whiteneck, G. G. (1993). Long-term spinal cord injury: functional changes over time. Arch. Phys. Med. Rehabil. 74, 1030-1034. doi: 10.1016/0003-9993(93)90057-h

Gleichmann, M., and Mattson, M. P. (2011). Neuronal calcium homeostasis and dysregulation. Antioxid. Redox Signal. 14, 1261-1273. doi: 10.1089/ars.2010. 3386

Gonzalez, H., Olsson, T., and Borg, K. (2010). Management of postpolio syndrome. Lancet Neurol. 9, 634-642. doi: 10.1016/S1474-4422(10)70095-8

Griffin, L., Godfrey, S., and Thomas, C. K. (2002). Stimulation pattern that maximizes force in paralyzed and control whole thenar muscles. J. Neurophysiol. 87, 2271-2278. doi: 10.1152/jn.01002.2002

Grimby, G., Stalberg, E., Sandberg, A., and Sunnerhagen, K. S. (1998). An 8year longitudinal study of muscle strength, muscle fiber size and dynamic electromyogram in individuals with late polio. Muscle Nerve 21, 1428-1437. doi: 10.1002/(SICI) 1097-4598(199811)21:11<1428::AID-MUS10>3.0.CO;2-X

Guest, J. D., Hiester, E. D., and Bunge, R. P. (2005). Demyelination and Schwann cell responses adjacent to injury epicenter cavities following chronic human spinal cord injury. Exp. Neurol. 192, 384-393. doi: 10.1016/j.expneurol.2004.11.033

Gwak, Y. S., Hains, B. C., Johnson, K. M., and Hulsebosch, C. E. (2004). Effect of age at time of spinal cord injury on behavioral outcomes in rat. J. Neurotrauma 21, 983-993. doi: 10.1089/0897715041650999

Häger-Ross, C. K., Klein, C. S., and Thomas, C. K. (2006). Twitch and tetanic properties of human thenar motor units paralyzed by chronic spinal cord injury. J. Neurophysiol. 96, 165-174. doi: 10.1152/jn.01339.2005

Harding, D. I., Greensmith, L., and Vrbová, G. (1999). Stabilizing neuromuscular contacts reduces motoneuron death caused by paralysis of muscles in neonatal rats. Neuroscience 93, 1141-1146. doi: 10.1016/s0306-4522(99)00 184-0

Hayes, K. C., and Kakulas, B. A. (1997). Neuropathology of human spinal cord injury sustained in sports-related activities. J. Neurotrauma 14, 235-248. doi: 10. 1089/neu.1997.14.235

Hayward, M., and Seaton, D. (1979). Late sequelae of paralytic poliomyelitis: a clinical and electromyographic study. J. Neurol. Neurosurg. Psychiatry 42, 117122. doi: $10.1136 /$ jnnp.42.2.117

Hennig, R., and Lømo, T. (1985). Firing patterns of motor units in normal rats. Nature 314, 164-166. doi: 10.1038/314164a0

Jackson, A. B., Dijkers, M., DeVivo, M. J., and Poczatek, R. B. (2004). A demographic profile of new traumatic spinal cord injuries: change and stability over 30 years. Arch. Phys. Med. Rehabil. 85, 1740-1748. doi: 10.1016/j.apmr.2004.04. 035

Jacobs, R. A., Díaz, V., Soldini, L., Haider, T., Thomassen, M., Nordsborg, N. B., et al. (2013). Fast-twitch glycolytic skeletal muscle is predisposed to age-induced impairments in mitochondrial function. J. Gerontol. A Biol. Sci. Med. Sci. 68, 1010-1022. doi: 10.1093/gerona/gls335
Jaerve, A., Schiwy, N., Schmitz, C., and Mueller, H. W. (2011). Differential effect of aging on axon sprouting and regenerative growth in spinal cord injury. Exp. Neurol. 231, 284-294. doi: 10.1016/j.expneurol.2011.07.002

Jubelt, B., Narayan, O., and Johnson, R. T. (1980). Pathogenesis of human poliovirus infection in mice. II. Age-dependency of paralysis. J. Neuropathol. Exp. Neurol. 39, 149-159. doi: 10.1097/00005072-198003000-00004

Kemp, B., and Thompson, L. (2002). Aging and spinal cord injury: medical, functional and psychosocial changes. SCI Nurs. 19, 51-60.

Kern, D. S., Semmler, J. G., and Enoka, R. M. (2001). Long-term activity in upper- and lower-limb muscles of humans. J. Appl. Physiol. 91, 22242232.

Kern, H., Rossini, K., Carraro, U., Mayr, W., Vogelauer, M., Hoellwarth, U., et al. (2005). Muscle biopsies show that FES of denervated muscles reverses human muscle degeneration from permanent spinal motoneuron lesion. J. Rehabil. Res. Dev. 42, 43-53. doi: 10.1682/jrrd.2004.05.0061

Kirshblum, S., Millis, S., McKinley, W., and Tulsky, D. (2004). Late neurologic recovery after traumatic spinal cord injury. Arch. Phys. Med. Rehabil. 85, 18111817. doi: 10.1016/j.apmr.2004.03.015

Klein, C. S., Hager-Ross, C. K., and Thomas, C. K. (2006). Fatigue properties of human thenar motor units paralysed by chronic spinal cord injury. J. Physiol. 573, 161-171. doi: 10.1113/jphysiol.2005.103044

Klein, C. S., Peterson, L. B., Ferrell, S., and Thomas, C. K. (2010). Sensitivity of 24-h EMG duration and intensity in the human vastus lateralis muscle to threshold changes. J. Appl. Physiol. (1985) 108, 655-661. doi: 10.1152/japplphysiol.00757. 2009

Krause, J. S., and Coker, J. L. (2006). Aging after spinal cord injury: a 30-year longitudinal study. J. Spinal Cord Med. 29, 371-376.

Lauretani, F., Russo, C. R., Bandinelli, S., Bartali, B., Cavazzini, C., Di, I. A., et al. (2003). Age-associated changes in skeletal muscles and their effect on mobility: an operational diagnosis of sarcopenia. J. Appl. Physiol. 95, 18511860 .

McColl, M. A., Charlifue, S., Glass, C., Savic, G., and Meehan, M. (2002). International differences in ageing and spinal cord injury. Spinal Cord 40, 128-136. doi: 10.1038/sj.sc.3101264

McComas, A. J., Galea, V., and de Bruin, H. (1993). Motor unit populations in healthy and diseased muscles. Phys. Ther. 73, 868-877.

McComas, A. J., Quartly, C., and Griggs, R. C. (1997). Early and late losses of motor units after poliomyelitis. Brain 120, 1415-1421. doi: 10.1093/brain/120.8. 1415

Mulcahey, M. J., Smith, B. T., and Betz, R. R. (1999). Evaluation of the lower motor neuron integrity of upper extremity muscles in high level spinal cord injury. Spinal Cord 37, 585-591. doi: 10.1038/sj.sc.3100889

National Spinal Cord Injury Statistical Center (NSCISC). Available at: https:// www.nscisc.uab.edu/PublicDocuments/fact_figures_docs/Facts\%2013.pdf

Needham-Shropshire, B. M., Klose, K. J., Tucker, M. E., and Thomas, C. K. (1997). Manual muscle test score and force comparisons after cervical spinal cord injury. J. Spinal Cord Med. 20, 324-330.

Peckham, P. H., Mortimer, J. T., and Marsolais, E. B. (1976a). Alteration in the force and fatigability of skeletal muscle in quadriplegic humans following exercise induced by chronic electrical stimulation. Clin. Orthop. Relat. Res. 114, 326333.

Peckham, P. H., Mortimer, J. T., and Marsolais, E. B. (1976b). Upper and lower motor neuron lesions in the upper extremity muscles of tetraplegics. Paraplegia 14, 115-121. doi: 10.1038/sc.1976.19

Pedersen, B. K. (2009). The diseasome of physical inactivity-and the role of myokines in muscle-fat cross talk. J. Physiol. 587, 5559-5568. doi: 10. 1113/jphysiol.2009.179515

Pierotti, D. J., Roy, R. R., Bodine-Fowler, S. C., Hodgson, J. A., and Edgerton, V. R. (1991). Mechanical and morphological properties of chronically inactive cat tibialis anterior motor units. J. Physiol. 444, 175-192.

Pouw, M. H., Hosman, A. J., van, K. A., Hirschfeld, S., Thietje, R., and van de, M. H. (2011). Is the outcome in acute spinal cord ischaemia different from that in traumatic spinal cord injury? A cross-sectional analysis of the neurological and functional outcome in a cohort of 93 paraplegics. Spinal Cord 49, 307-312. doi: 10.1038/sc.2010.114

Rosen, B., and Lundborg, G. (2001). The long term recovery curve in adults after median or ulnar nerve repair: a reference interval. J. Hand Surg. Br. 26, 196-200. doi: 10.1054/jhsb.2001.0567 
Shields, R. K., and Dudley-Javoroski, S. (2006). Musculoskeletal plasticity after acute spinal cord injury: effects of long-term neuromuscular electrical stimulation training. J. Neurophysiol. 95, 2380-2390. doi: 10.1152/jn.01181.2005

Siegenthaler, M. M., Ammon, D. L., and Keirstead, H. S. (2008). Myelin pathogenesis and functional deficits following SCI are age-associated. Exp. Neurol. 213, 363-371. doi: 10.1016/j.expneurol.2008.06.015

Stein, R. B., Brucker, B. S., and Ayyar, D. R. (1990). Motor units in incomplete spinal cord injury: electrical activity, contractile properties and the effects of biofeedback. J. Neurol. Neurosurg. Psychiatry 53, 880-885. doi: 10.1136/jnnp.53. 10.880

Stein, R. B., Gordon, T., Jefferson, J., Sharfenberger, A., Yang, J. F., Tötösy de Zepetnek, J., et al. (1992). Optimal stimulation of paralyzed muscle after human spinal cord injury. J. Appl. Physiol. 72, 1393-1400.

Thomas, C. K. (1997). Contractile properties of human thenar muscles paralyzed by spinal cord injury. Muscle Nerve 20, 788-799. doi: 10.1002/(sici)10974598(199707)20:7<788::aid-mus2>3.0.co;2-3

Thomas, C. K., Broton, J. G., and Calancie, B. (1997). Motor unit forces and recruitment patterns after cervical spinal cord injury. Muscle Nerve 20, 212-220. doi: 10.1002/(sici)1097-4598(199702)20:2<212::aid-mus12>3.0.co;2-4

Thomas, C. K., Griffin, L., Godfrey, S., Ribot-Ciscar, E., and Butler, J. E. (2003). Fatigue of paralyzed and control thenar muscles induced by variable or constant frequency stimulation. J. Neurophysiol. 89, 2055-2064. doi: 10.1152/jn.01002. 2002

Thomas, C. K., Hager-Ross, C. K., and Klein, C. S. (2010). Effects of baclofen on motor units paralysed by chronic cervical spinal cord injury. Brain 133, 117125. doi: 10.1093/brain/awp285

Thomas, C. K., Johansson, R. S., and Bigland-Ritchie, B. (1991). Attempts to physiologically classify human thenar motor units. J. Neurophysiol. 65, 15011508.

Thomas, C. K., Johansson, R. S., and Bigland-Ritchie, B. (2006). EMG changes in human thenar motor units with force potentiation and fatigueaa. J. Neurophysiol. 95, 1518-1526. doi: 10.1152/jn.00924.2005

Thomas, C. K., Nelson, G., Than, L., and Zijdewind, I. (2002). Motor unit activation order during electrically evoked contractions of paralyzed or partially paralyzed muscles. Muscle Nerve 25, 797-804. doi: 10.1002/mus.10111

Thomas, C. K., Peterson, L. B., Klein, C. S., Ferrell, S., Winslow, J., and Tepavac, D. (2005). Daily use of human thenar muscles. Soc. Neurosci. Abs. 397.7. Available at: http://www.sfn.org/Annual-Meeting/Past-and-FutureAnnual-Meetings/Abstract-Archive/Abstract-Archive-Detail

Thomas, C. K., and Zijdewind, I. (2006). Fatigue of muscles weakened by death of motoneurons. Muscle Nerve 33, 21-41. doi: 10.1002/mus.20400

Tower, S. S. (1937). Function and structure in the chronically isolated lumbosacral spinal cord of the dog. J. Comp. Neurol. 67, 109-131. doi: 10.1002/cne. 900670107 van den Bosch, L., Van Damme, P., Bogaert, E., and Robberecht, W. (2006) The role of excitotoxicity in the pathogenesis of amyotrophic lateral sclerosis. Biochim. Biophys. Acta 1762, 1068-1082. doi: 10.1016/j.bbadis.2006. 05.002

Vandervoort, A. A. (2002). Aging of the human neuromuscular system. Muscle Nerve 25, 17-25. doi: 10.1002/mus.1215

Waters, R. L., Adkins, R. H., Yakura, J. S., and Sie, I. (1993). Motor and sensory recovery following complete tetraplegia. Arch. Phys. Med. Rehabil. 74, 242-247.

Weinstein, L. (1957). Influence of age and sex on susceptibility and clinical manifestations in poliomyelitis. N. Engl. J. Med. 257, 47-52. doi: 10. 1056/nejm195707112570201

Westling, G., Johansson, R. S., Thomas, C. K., and Bigland-Ritchie, B. (1990). Measurement of contractile and electrical properties of single human thenar motor units in response to intraneural motor-axon stimulation. J. Neurophysiol. 64, 1331-1338.

White, C. M., Greensmith, L., and Vrbova, G. (2000). Repeated stimuli for axonal growth causes motoneuron death in adult rats: the effect of botulinum toxin followed by partial denervation. Neuroscience 95, 1101-1109. doi: 10.1016/s03064522(99)00512-6

Yang, J. F., Stein, R. B., Jhamandas, J., and Gordon, T. (1990). Motor unit numbers and contractile properties after spinal cord injury. Ann. Neurol. 28, 496-502. doi: 10.1002/ana.410280405

Zijdewind, I., and Thomas, C. K. (2001). Spontaneous motor unit behavior in human thenar muscles after spinal cord injury. Muscle Nerve 24, 952-962. doi: 10.1002/mus.1094.abs

Zijdewind, I., and Thomas, C. K. (2012). Firing patterns of spontaneously active motor units in spinal cord-injured subjects. J. Physiol. 590, 1683-1697. doi: 10. 1113/jphysiol.2011.220103

Conflict of Interest Statement: The authors declare that the research was conducted in the absence of any commercial or financial relationships that could be construed as a potential conflict of interest.

Received: 26 September 2013; accepted 06 January 2014; published online: 23 January 2014.

Citation: Thomas CK and Grumbles RM (2014) Age at spinal cord injury determines muscle strength. Front. Integr. Neurosci. 8:2. doi: 10.3389/fnint.2014.00002 This article was submitted to the journal Frontiers in Integrative Neuroscience. Copyright (c) 2014 Thomas and Grumbles. This is an open-access article distributed under the terms of the Creative Commons Attribution License (CC BY). The use, distribution or reproduction in other forums is permitted, provided the original author(s) or licensor are credited and that the original publication in this journal is cited, in accordance with accepted academic practice. No use, distribution or reproduction is permitted which does not comply with these terms. 